\title{
Effects of higher PEEP and recruitment manoeuvres on mortality in patients with ARDS: a systematic review, meta-analysis, meta-regression and trial sequential analysis of randomized controlled trials
}

\author{
Lorenzo Ball ${ }^{1,2,3^{*}}$ (D), Ary Serpa Neto ${ }^{3,4}$, Valeria Trifiletti ${ }^{1}$, Maura Mandelli ${ }^{1}$, lacopo Firpo ${ }^{1}$, Chiara Robba ${ }^{2}$,
}

Marcelo Gama de Abreu ${ }^{5}$, Marcus J. Schultz ${ }^{3,6,7}$, Nicolò Patroniti ${ }^{1,2}$, Patricia R. M. Rocco ${ }^{8}$, Paolo Pelosi ${ }^{1,2}$ and For the PROVE Network: PROtective Ventilation Network

From 4th International Symposium on Acute Pulmonary Injury and Translational Research - INSPIRES 2019

Dresden, Germany. 25-26 November 2019

\footnotetext{
*Correspondence: lorenzo.ball@ edu.unige.it

${ }^{1}$ Department of Surgical Sciences and Integrated Diagnostics, University of Genova, Largo Rosanna Benzi 8, 16131 Genova, Italy

${ }^{2}$ Anesthesia and Intensive Care, Ospedale Policlinico San Martino IRCCS per l'Oncologia e le Neuroscienze, Genova, Italy Full list of author information is available at the end of the article
}

\begin{abstract}
Purpose: In patients with acute respiratory distress syndrome (ARDS), lung recruitment could be maximised with the use of recruitment manoeuvres (RM) or applying a positive end-expiratory pressure (PEEP) higher than what is necessary to maintain minimal adequate oxygenation. We aimed to determine whether ventilation strategies using higher PEEP and/or RMs could decrease mortality in patients with ARDS.

Methods: We searched MEDLINE, EMBASE and CENTRAL from 1996 to December 2019, included randomized controlled trials comparing ventilation with higher PEEP and/or RMs to strategies with lower PEEP and no RMs in patients with ARDS. We computed pooled estimates with a DerSimonian-Laird mixed-effects model, assessing mortality and incidence of barotrauma, population characteristics, physiologic variables and ventilator settings. We performed a trial sequential analysis (TSA) and a meta-regression.

Results: Excluding two studies that used tidal volume $\left(V_{\mathrm{T}}\right)$ reduction as cointervention, we included 3870 patients from 10 trials using higher PEEP alone $(n=$ 3), combined with RMs $(n=6)$ or RMs alone $(n=1)$. We did not observe differences in mortality (relative risk, RR 0.96, 95\% confidence interval, $\mathrm{Cl}$ [0.84-1.09], $p=0.50$ ) nor in incidence of barotrauma (RR 1.22, 95\% Cl [0.93-1.61], $p=0.16$ ). In the metaregression, the PEEP difference between intervention and control group at day 1 and the use of RMs were not associated with increased risk of barotrauma. The TSA reached the required information size for mortality $(n=2928)$, and the $z$-line surpassed the futility boundary.

(Continued on next page)
\end{abstract}

(c) The Author(s). 2020 Open Access This article is licensed under a Creative Commons Attribution 4.0 International License, which permits use, sharing, adaptation, distribution and reproduction in any medium or format, as long as you give appropriate credit to the original author(s) and the source, provide a link to the Creative Commons licence, and indicate if changes were made. The images or other third party material in this article are included in the article's Creative Commons licence, unless indicated otherwise in a credit line to the material. If material is not included in the article's Creative Commons licence and your intended use is not permitted by statutory regulation or exceeds the permitted use, you will need to obtain permission directly from the copyright holder. To view a copy of this licence, visit http://creativecommons.org/licenses/by/4.0/. 
(Continued from previous page)

Conclusions: At low $V_{T}$, the routine use of higher PEEP and/or RMs did not reduce mortality in unselected patients with ARDS.

Trial registration: PROSPERO CRD42017082035.

Keywords: Acute respiratory distress syndrome, Positive end-expiratory pressure, Mechanical ventilation

\section{Introduction}

Despite intense research, mortality of patients with acute respiratory distress syndrome (ARDS) remains high [1]. Respiratory support is mandatory in ARDS to maintain adequate gas exchange, but mechanical ventilation itself can contribute to further lung damage in a process referred to as ventilator-induced lung injury (VILI). The main determinants of VILI are high pressures and volumes and cyclic opening and closing of respiratory units [2]. Development of VILI may translate into an iatrogenic component of ARDS mortality, overlapping with that due to the underlying lung condition, and can be reduced by optimising mechanical ventilation [3].

Ventilation settings aimed to minimise VILI are referred to as 'protective mechanical ventilation'. However, different putative mechanisms of VILI have been targeted, and there is no unanimous consent on which ventilator settings should be considered 'protective' or 'more protective'. After the encouraging results of the first trials comparing bundles of interventions such as tidal volume $\left(V_{\mathrm{T}}\right)$ size reduction, positive endexpiratory pressure (PEEP) and recruitment manoeuvres (RMs) with conventional ventilation $[4,5]$, new debates have arisen to determine which of these parameters improved outcome. In a trial conducted by the ARDS network, both arms received the lowest $\mathrm{PEEP} / \mathrm{FIO}_{2}$ combination necessary to achieve an acceptable oxygenation; however, the group receiving $V_{\mathrm{T}}=6 \mathrm{~mL}$ per $\mathrm{kg}$ of predicted body weight (PBW) resulted in lower mortality compared to $12 \mathrm{~mL} / \mathrm{kg}$ [6].

Subsequently, the use of PEEP levels higher than those strictly required to maintain oxygenation ('higher' PEEP) with or without the concomitant use of RMs has been proposed in the so-called 'open lung approach' strategy, aimed at maximising lung recruitment during ventilation [7]. Accordingly, the authors proposed different methods to titrate PEEP, either based on oxygenation or respiratory mechanics goals, and trials investigated whether mortality could be further reduced by applying higher PEEP on a routine basis. A recent clinical practice guideline of the American Thoracic Society, European Society of Intensive Care Medicine and Society of Critical Care Medicine advocates the use of higher PEEP in patients with moderate or severe ARDS [8], based on the results of an individual data meta-analysi s[9]. However, this guideline was published before the latest trials and did not stratify studies according to the use of higher PEEP, RMs or their combination.

We conducted a systematic review and meta-analysis of RCTs comparing ventilation strategies comprising higher PEEP and/or RMs to conventional strategies with lower PEEP levels and no RMs, either used alone or in combination. We aimed to determine whether the routine use of higher PEEP and/or RMs could reduce mortality in ARDS patients. We hypothesized that the indiscriminate use of higher PEEP and/or RMs in all ARDS patients had no effect on mortality. 


\section{Methods}

\section{Data sources and searches}

This review evaluated randomised trials in patients with ARDS, which investigated ventilation strategies that included higher PEEP levels and/or RMs (intervention) versus fixed PEEP or PEEP increased stepwise enough only to reach minimal oxygenation goals (control). The eTable 1 contains details on patients, interventions, comparators and outcomes.

We classified as 'higher PEEP' any strategy resulting in or aimed at obtaining PEEP levels higher than those achieved in the control group, in which PEEP was kept at a fixed level or increased enough only to reach minimal adequate oxygenation goals. We considered 'RM' any transient increase in airway pressure aimed at restoring or improving lung aeration. We searched electronically MEDLINE, EMBASE and the Cochrane Controlled Trials Registers from 1996 to July 2019 for potentially relevant studies using a focused search strategy, whose details are provided in the online supplement. Bibliography of the selected studies was inspected for potential inclusion of other trials.

\section{Study selection, quality assessment and data extraction}

A primary search was conducted by two investigators (LB and PP) who evaluated the adherence to the inclusion criteria solving discrepancies by consensus, and when consensus was not reached a third investigator was consulted (PRMR). The trials were also assessed for potential sources of bias using the Cochrane Collaboration risk of bias instrument, assessing random sequence generation and allocation concealment, blinding of participants, personnel and outcome assessors, presence of incomplete outcome data or selective reporting and other potential sources of bias. Data extraction was performed independently by two authors (VT and MM), and discrepancies were solved by consensus.

\section{Outcomes}

The primary outcome was mortality at 28 days, substituted when not reported by mortality at 30 days, intensive care unit (ICU) discharge, hospital discharge or at 60 days, in this sequence as available in the analysed trial. This collapsed mortality end point was recently proposed by a panel of experts of the 'Mechanical Ventilation for ARDS Clinical Practice Guideline' taskforce [10]. Secondary outcomes were incidence of barotrauma, extrapulmonary complications and gas exchange and ventilation parameters. Barotrauma was defined as pneumothorax, pneumomediastinum or subcutaneous emphysema. We recorded the different definitions of extrapulmonary complications in the different included studies; however, as detailed in the results section, their heterogeneity was too high to perform a formal meta-analysis. We collected patients' characteristics at baseline, and ventilation and blood gas analysis data at 1, 3 and 7 days, or at the closest reported time point.

\section{Subgroup analyses}

We stratified the studies according to the type of intervention (higher PEEP, RMs or their combination). We further performed a pre-planned stratification only including patients with $\mathrm{PaO}_{2} / \mathrm{FIO}_{2} \leq 200 \mathrm{mmHg}$ at randomisation and a post-hoc stratification 
comparing studies that titrated higher PEEP based on oxygenation or respiratory mechanics goals. Outcome data for subgroups were collected where available. For three trials [11-13], data of this sub-group was extracted from the pooled stratum reported in an individual patient meta-analysis [9].

\section{Sensitivity analyses}

To assess whether the control groups were representative of the current practice of ventilation of ARDS patients, we compared their baseline characteristics and ventilator settings after enrolment with the median values extrapolated from the 'Large observational study to UNderstand the Global impact of Severe Acute respiratory FailurE' (LUNG SAFE) [1]. Moreover, we performed a meta-regression to evaluate the influence on the effect size of the following parameters: method of setting PEEP, fraction of pulmonary ARDS at enrolment, use of recruitment manoeuvres, $\mathrm{PaO}_{2} / \mathrm{FIO}_{2}$ ratio at randomisation, PEEP difference between treatment and control at the time point closest to day 1.

Data synthesis and analysis

For dichotomous outcomes, we computed the relative risks (RRs) with their 95\% confidence intervals (CIs). For continuous variables describing patients' characteristics and parameters at baseline and at different time points, we computed the pooled average and standard deviation (SD) of each group and their mean difference. All estimates were calculated with a mixed-effects model using the DerSimonian-Laird method and a continuity correction constant of 0.5 . Potential bias for the primary outcome was examined with a funnel plot of treatment effect versus study precision, with an Egger test for plot asymmetry. Subgroups were compared with the Cochran's $Q$ test, and residual heterogeneity was assessed with the $I^{2}$ statistics and $Q$ test. Comparisons between the control group and the median values reported in the LUNG SAFE study were performed with one-sampled Student's $t$ tests. We conducted a formal trial sequential analysis (TSA) limiting the global type I error to 5\%, computing the two-sided $\alpha$-spending boundaries and futility area with the O'Brien-Fleming function. This method provides conservative $\mathrm{CI}$ estimates for the effect size, similar to what is done in ad interim analyses in RCTs. We hypothesized a pooled mortality rate of $35 \%$ in the control arm, and we aimed to achieve $90 \%$ power (1- $\beta$ ) to detect a $25 \%$ relative risk reduction in the intervention arm.

All analyses were performed with R 3.2.3 and the metafor and meta packages (The R Foundation for Statistical Computing, www.r-project.org), RevMan 5.3 (Cochrane Collaboration, Copenhagen, Denmark) and TSA 0.9.5.10 (Copenhagen Trial Unit, Copenhagen, Denmark). Statistical significance was considered for two-tailed $p<0.05$. The protocol had been registered in the Prospero database (CRD42017082035).

\section{Results}

Figure 1 depicts the study inclusion flow, and Table 1 shows the description of the included studies. Overall, risk of bias was moderate-low (eFigures 1 and 2). We found six studies using higher PEEP plus RMs [11, 14-18], three using higher PEEP alone [12, 13, 19] and one using RMs alone [20]. We also found two studies [4, 5] in which higher PEEP and RMs were used in conjunction with $V_{\mathrm{T}}$ reduction, but we did not consider 


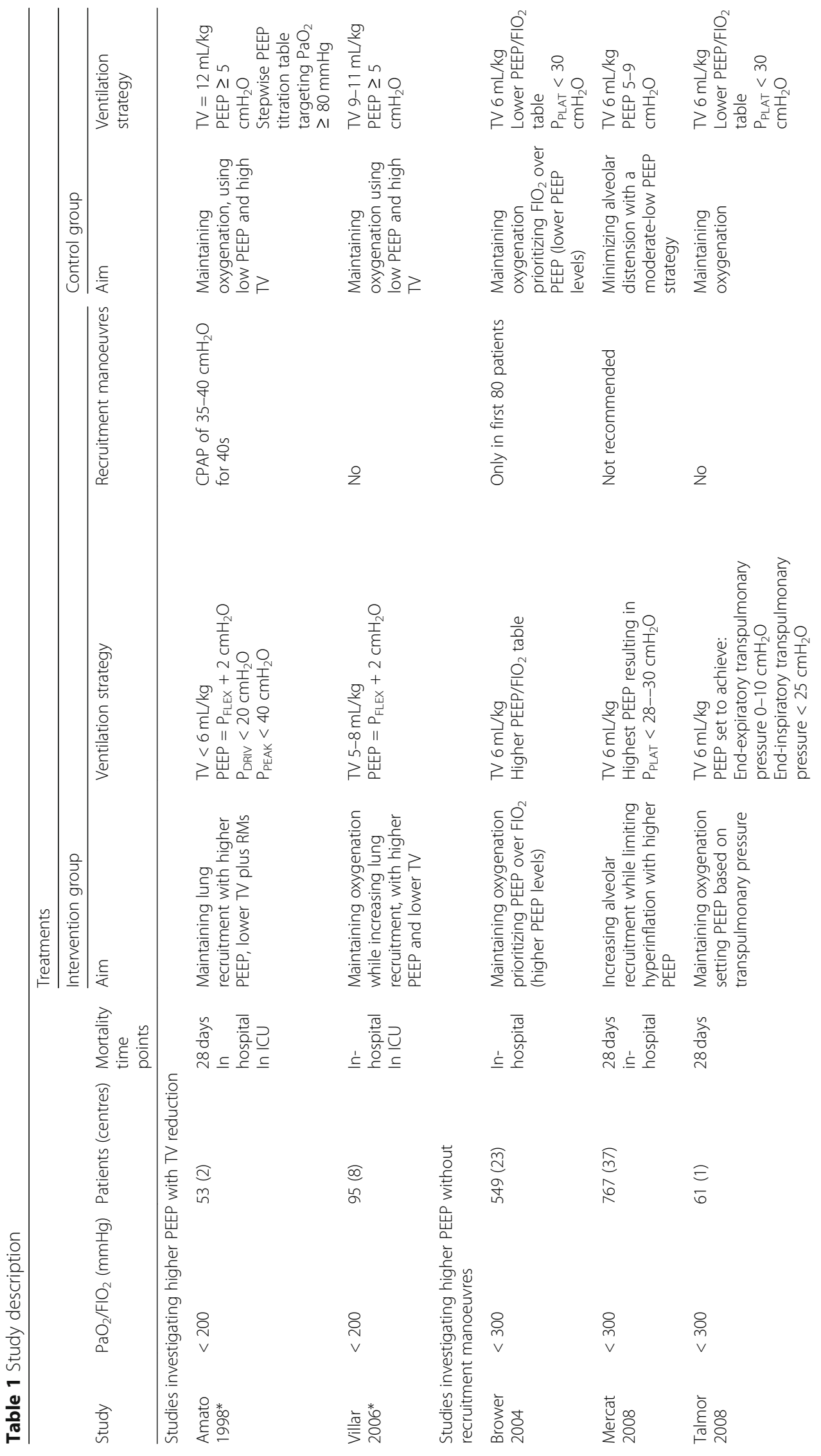




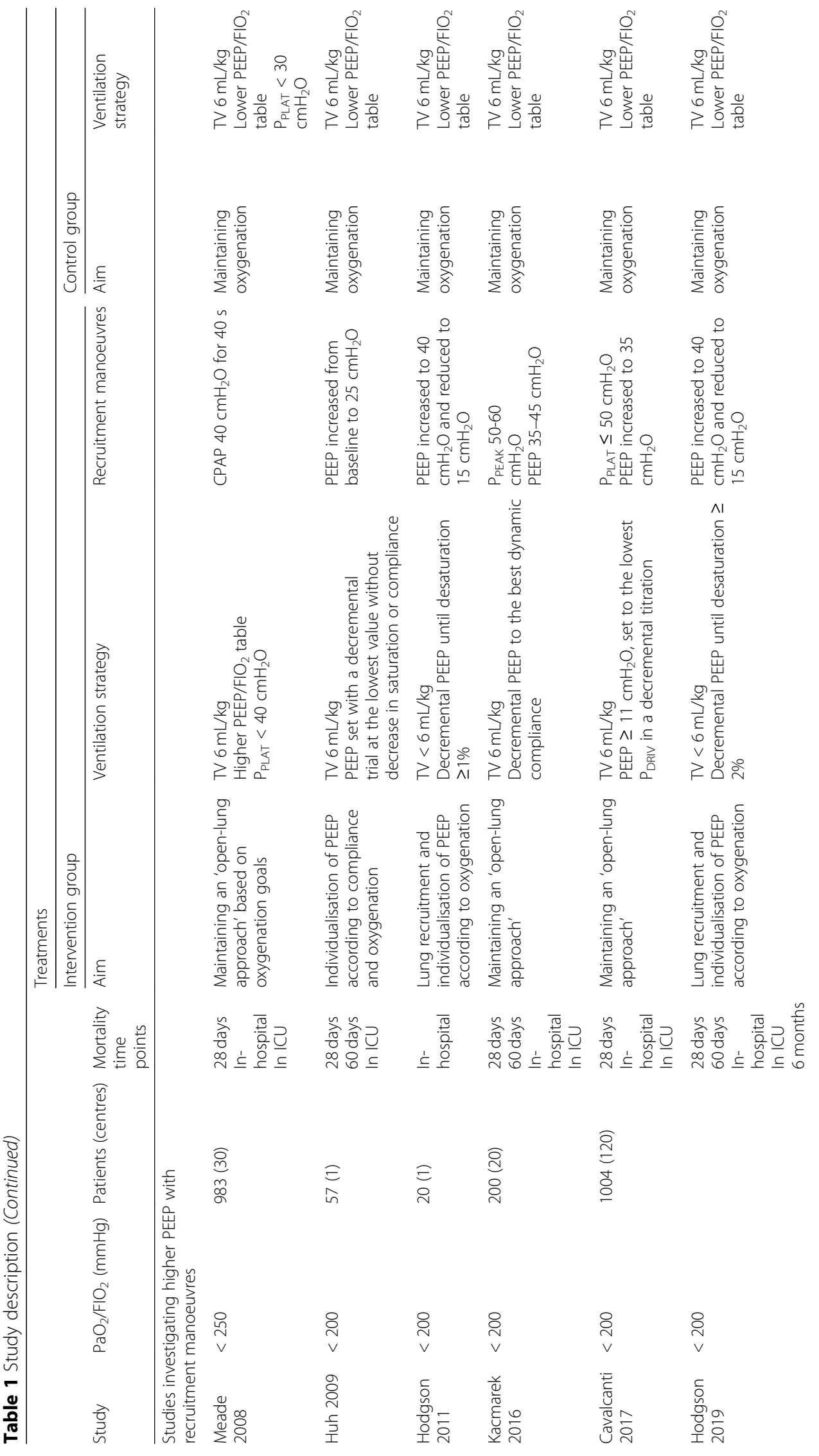




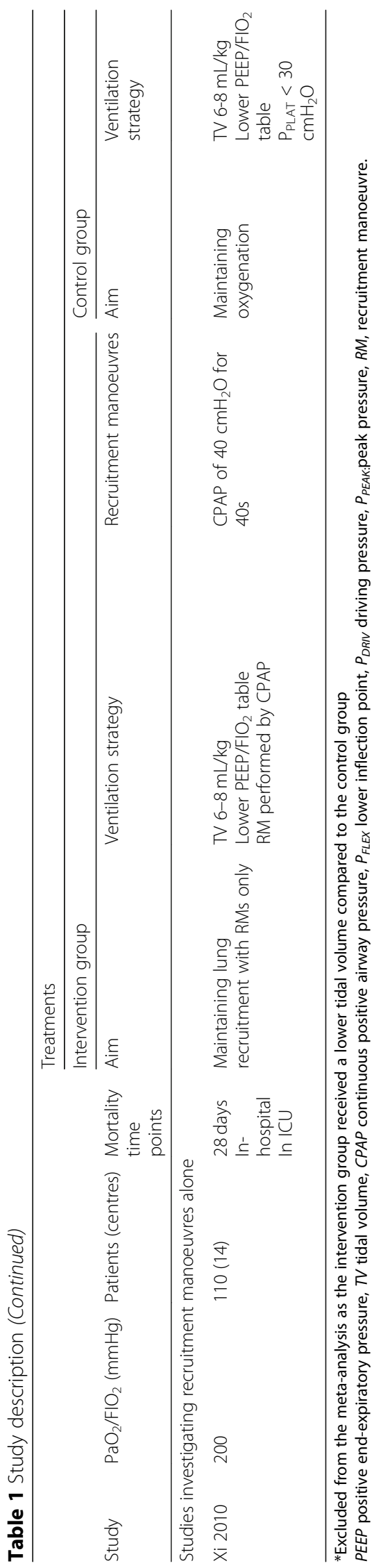


these studies in the meta-analysis since their inclusion resulted in high clinical and statistical heterogeneity (see eFigure 3).

We included 3870 patients in the meta-analysis, whose baseline characteristics are reported in Table 2. As shown in Table 3, in the intervention versus control group at days 1, 3 and 7 from randomisation, there were no differences in $V_{\mathrm{T}}$ size or respiratory rate, while PEEP and $\mathrm{PaO}_{2} / \mathrm{FIO}_{2}$ ratio were consistently higher. Driving pressure was lower in the intervention group at days 1 and 3, but not at day 7. Plateau pressure was higher in the intervention group at days 1 and 3 , but not at day 7. We did not observe differences in mortality (RR $0.96,95 \%$ confidence interval, CI [0.84-1.09], $p=0.50$, Fig. 2, funnel plot in Fig. 3) nor in incidence of barotrauma (RR 1.22, 95\% CI [0.93-1.61], $p=0.16$, eFigure 4) in the pooled analysis. Stratification according to the different combination of PEEP/RM intervention reduced statistical heterogeneity, but still no differences in mortality (Fig. 2) nor barotrauma (eFigure 4) were observed. Mortality at day 28 (eFigure 5), ICU discharge (eFigure 6), hospital discharge (eFigure 7) and at day 60 (eFigure 8) was not different between groups. No differences in mortality or incidence of barotrauma were observed when analysis was restricted to studies including only patients with $\mathrm{PaO}_{2} / \mathrm{FIO}_{2}$ below $200 \mathrm{mmHg}$ at enrolment (e-Figures 9 and 10). Extrapulmonary complications, ventilator- and organ failure-free days were reported

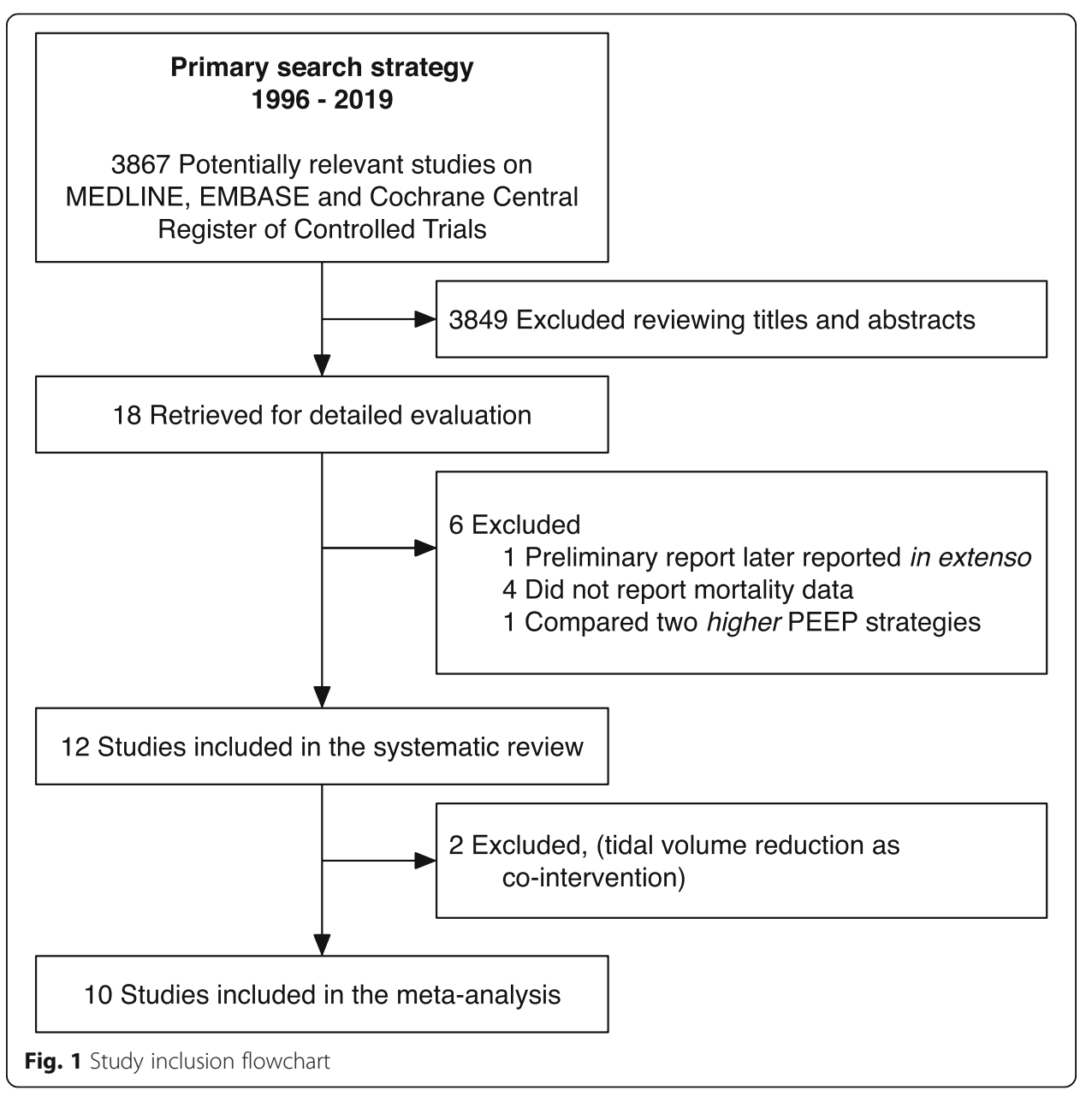


Table 2 Baseline characteristics of patients included in the meta-analysis

\begin{tabular}{|c|c|c|}
\hline Parameter & Intervention $(n=1918)$ & Control $(n=1952)$ \\
\hline Age, years & $55.7(3.2)[n=1919]$ & $56.1(5.3)[n=1952]$ \\
\hline Women, No (\%) & $732(38)[n=1918]$ & $750(38)[n=1952]$ \\
\hline $\mathrm{PaO}_{2} / \mathrm{FlO}_{2}$ at enrolment, $\mathrm{mmHg}$ & $135.8(14.4)[n=1859]$ & $134.7(17.4)[n=1892]$ \\
\hline Respiratory system compliance, $\mathrm{mL} / \mathrm{cmH}_{2} \mathrm{O}$ & $32.9(5.1)[n=969]$ & $32.0(4.4)[n=975]$ \\
\hline \multicolumn{3}{|l|}{ Causes of lung injury } \\
\hline Pneumonia, No. (\%) & $920(49)[n=1878]$ & $933(49)[n=1911]$ \\
\hline Aspiration, No. (\%) & $175(13)[n=1373]$ & $185(13)[n=1376]$ \\
\hline Sepsis, No. (\%) & $495(26)[n=1908]$ & $538(28)[n=1942]$ \\
\hline Multiple trauma, No. (\%) & $54(4)[n=1394]$ & $72(5)[n=1432]$ \\
\hline \multicolumn{3}{|l|}{ Ventilation parameters } \\
\hline Tidal volume, $\mathrm{mL} / \mathrm{kg}$ of predicted body weight & $7.3(1.1)[n=1909]$ & $7.4(1.2)[n=1942]$ \\
\hline Set PEEP, $\mathrm{cmH}_{2} \mathrm{O}$ & $11.2(1.8)[n=1643]$ & $11.1(2.1)[n=1679]$ \\
\hline Driving pressure, $\mathrm{CmH}_{2} \mathrm{O}$ & $15.4(2.4)[n=1575]$ & $15.2(2.1)[n=1615]$ \\
\hline Plateau pressure, $\mathrm{cmH}_{2} \mathrm{O}$ & $27.0(2.8)[n=1575]$ & $26.8(2.7)[n=1615]$ \\
\hline
\end{tabular}

Data are mean (standard deviation) or frequency (proportion). Number of patients for each variable is also reported, as data was missing or not reported as mean in all studies. Values are estimated means (standard deviations) calculated with a mixed-effects model using the DerSimonian-Laird method. PEEP positive end-expiratory pressure

heterogeneously from a clinical and statistical point of view, and a formal metaanalysis was not feasible.

In the trial sequential analysis, the required information size of 2928 was reached, and the cumulative Z-score did not cross the alpha-spending nor the conventional $95 \%$ boundaries, meaning that significance was not reached, but entered the futility wedge (Fig. 4).

\section{Sensitivity and post-hoc analyses}

At the meta-regression analysis, no association with mortality nor barotrauma was found for PEEP titration method, percent of patients with pulmonary versus extra-pulmonary ARDS, use of $\mathrm{RMs}, \mathrm{PaO}_{2} / \mathrm{FIO}_{2}$ ratio at randomisation and difference in PEEP at day $1(p>0.29$ for all covariates, details in e-tables 2 and 3).

No differences in mortality were observed when stratifying the analysis according to whether PEEP was set based on oxygenation or respiratory mechanics targets (e-Figures 11 and 12).

Compared to the population of the LUNG SAFE study, the control group of this meta-analysis included patients ventilated with lower $V_{\mathrm{T}}(p<0.001)$, while no differences were observed in age $(p=0.36)$, PEEP levels $(p=0.42)$, plateau pressure $(p=$ $0.53)$, respiratory rate $(p=0.68), \mathrm{FIO}_{2}(p=0.23), \mathrm{PaO}_{2} / \mathrm{FIO}_{2}$ ratio $(p=0.44)$ and $\mathrm{PaCO}_{2}(p=0.91)$.

\section{Discussion}

The main finding of the present meta-analysis was that, in unselected patients with ARDS who were mechanically ventilated with protective low $V_{\mathrm{T}}$, the use of higher PEEP and/or RMs does not result in mortality reduction nor incidence of barotrauma 


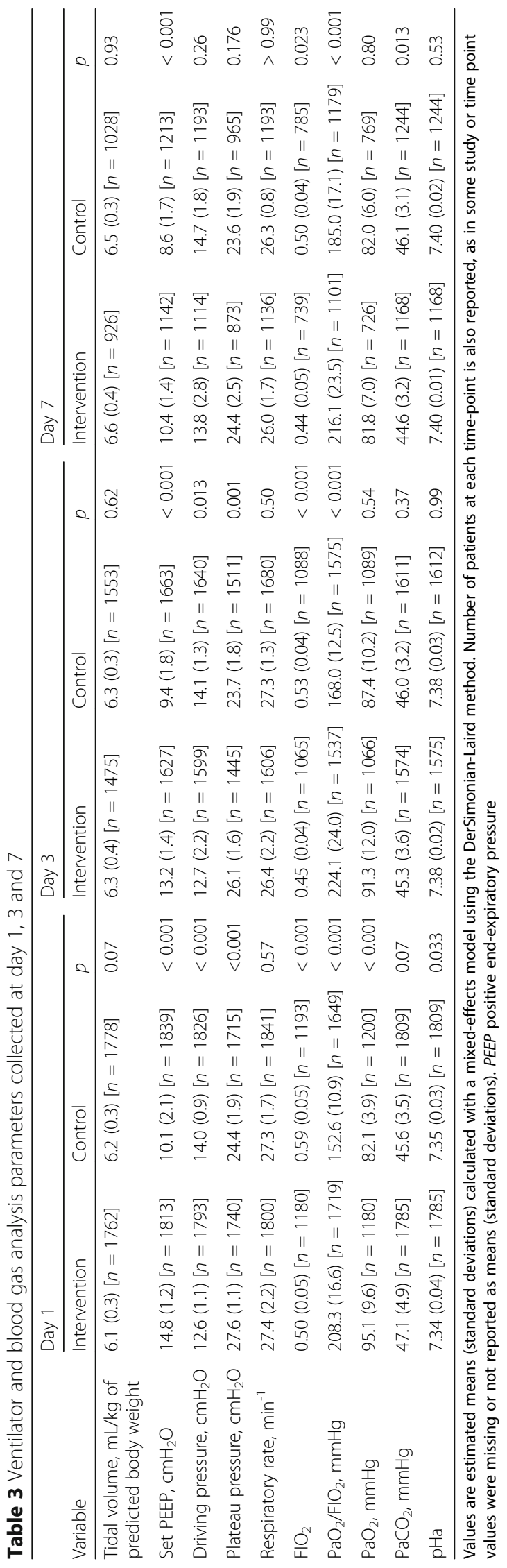




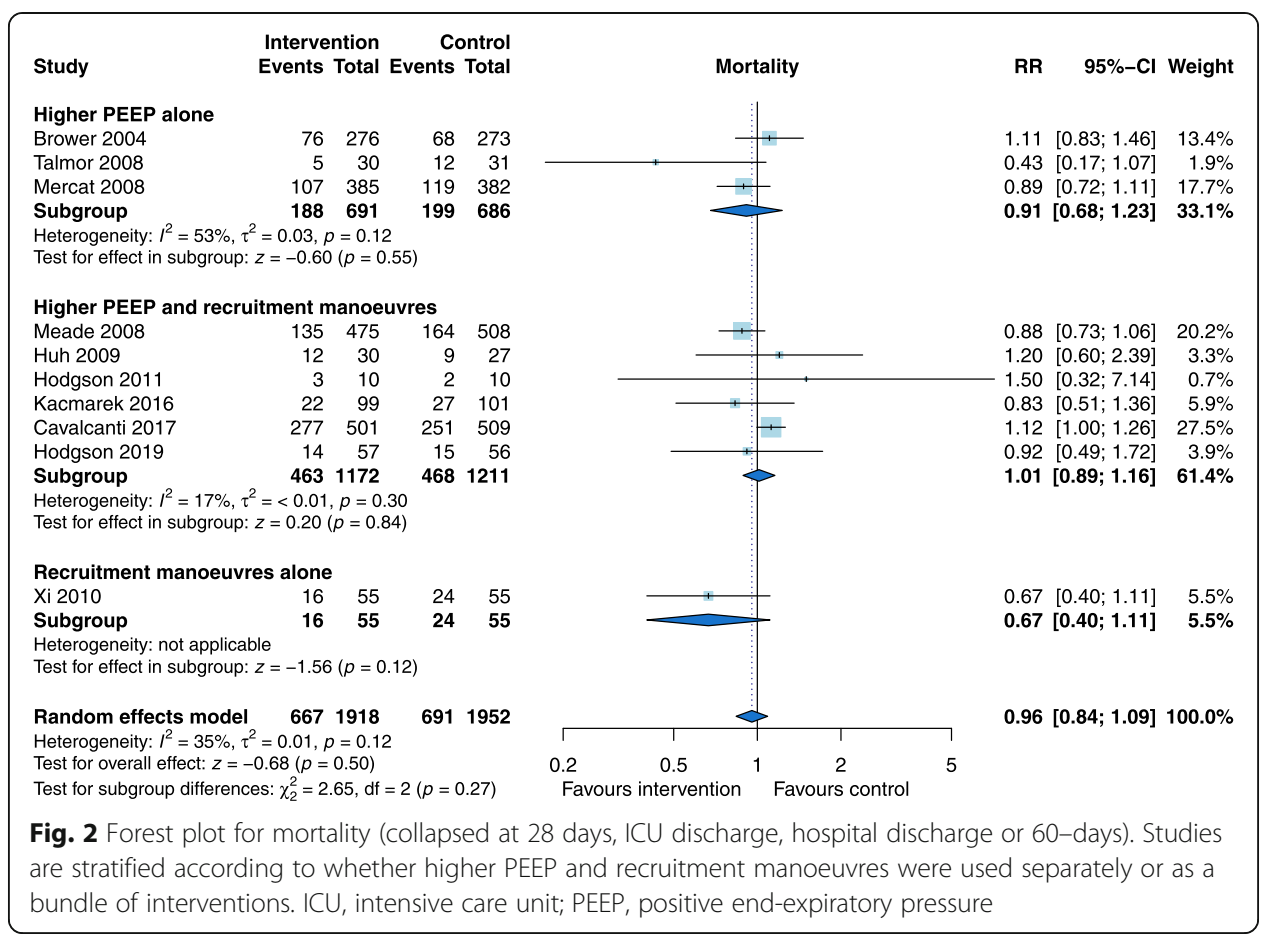

compared to a strategy using a PEEP level aimed at achieving minimal acceptable oxygenation goals.

This meta-analysis has several strengths. First, we restricted it to trials not changing $V_{\mathrm{T}}$ between groups, to avoid a relevant confounding factor. Second, we stratified the studies according to the type of co-interventions when feasible, to reduce the clinical and statistical heterogeneity. Third, we conducted a formal trial sequential analysis to

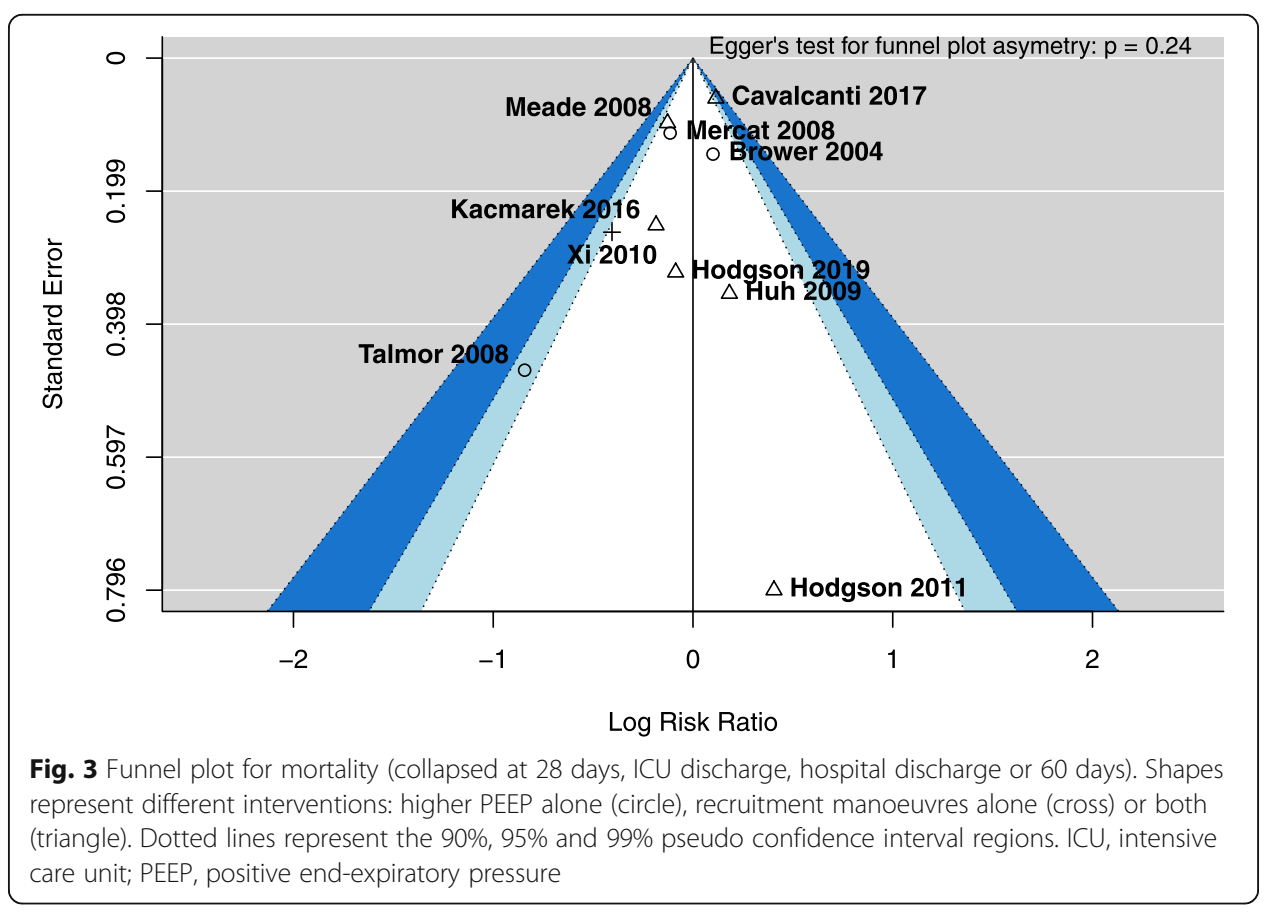




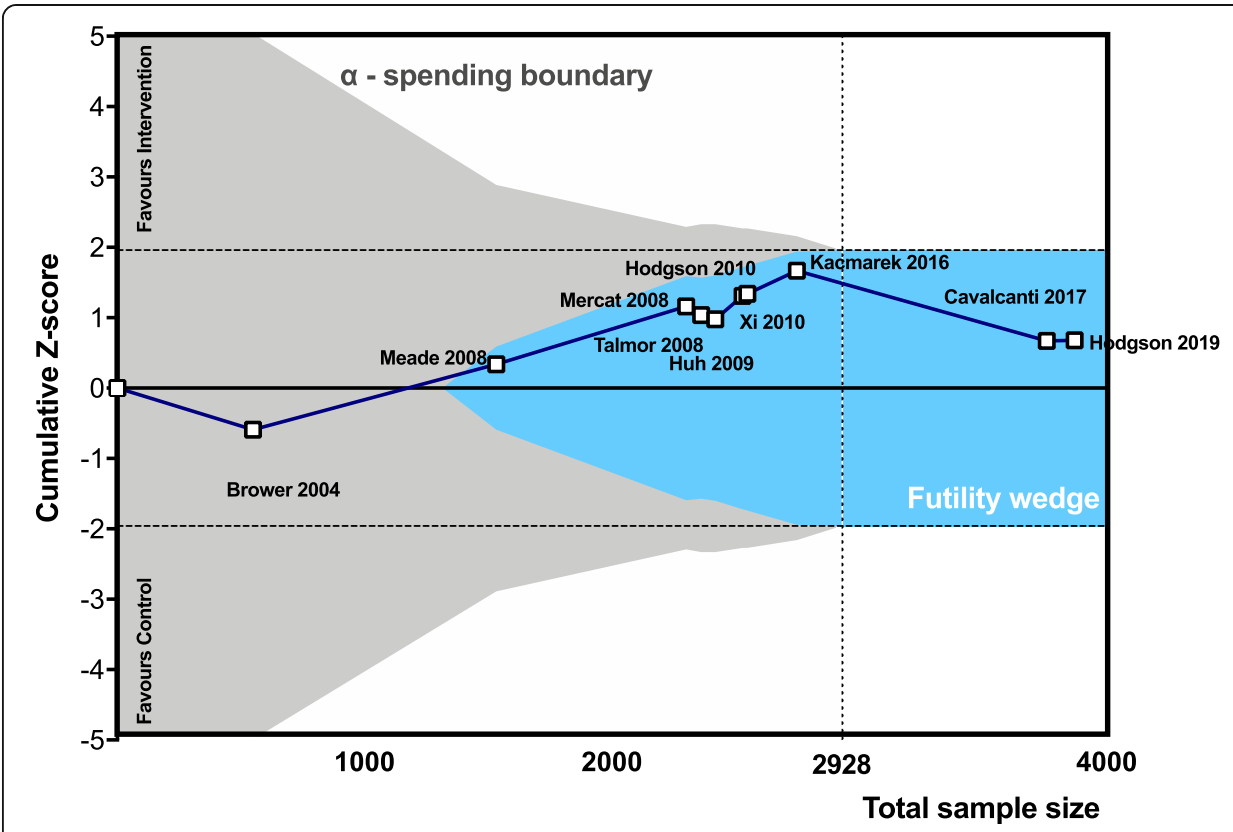

Fig. 4 Trial sequential analysis assessing the effects of PEEP and/or recruitment manoeuvres on mortality (collapsed at 28 days, ICU discharge, hospital discharge). Required information size of 2487 patients (dotted line) is calculated for a relative risk reduction of $25 \%, a=5 \%$, power $(1-\beta)=80 \%$. The Z-line (blue line) of the cumulative meta-analysis of 3757 patients did not cross the efficacy monitoring boundaries for benefit or harm (grey area) but entered the futility wedge (light blue area). Horizontal dashed lines represent the conventional level of significance $(p=0.05)$

assess the conclusiveness of the available evidence. Fourth, we conducted several preplanned and post-hoc analyses including meta-regression and conventional stratification to explore for meaningful associations.

In the pooled analysis, the average PEEP was around 15 and $10 \mathrm{cmH}_{2} \mathrm{O}$ in the intervention and control groups, respectively. The latter reflects the current practice of ventilation in ARDS patients, while $V_{\mathrm{T}}$ was lower than what is currently used [1]. As previously discussed in another systematic review, mortality improvement was only observed when PEEP increase is used in conjunction with a reduction of $V_{\mathrm{T}}$ size [21]. Regardless of the combination of PEEP/RM interventions, we did not observe any improvement in mortality when pooling data from different studies. In an individual patient meta-analysis published in 2010 [9] including patients enrolled in three trials [11-13], an improvement in mortality was observed in patients with a $\mathrm{PaO}_{2} / \mathrm{FIO}_{2} \leq$ $200 \mathrm{mmHg}$ at randomisation. However, following these encouraging findings, all studies published thereafter only included patients with moderate to severe ARDS, without showing improvements in mortality $[15-17,20]$. Nonetheless, a recent guideline recommends the use of higher PEEP levels in moderate to severe ARDS patients [8], but stresses the importance to balance between the advantages in lung recruitment and the risk of reaching elevated plateau pressures. In our pooled analysis, average plateau pressure was below $30 \mathrm{cmH}_{2} \mathrm{O}$ in both arms; however one trial reports that, with higher PEEP, plateau pressure can transiently cross this threshold more frequently as compared to lower PEEP [17].

A recent study found that high driving pressure (plateau pressure minus PEEP) is strongly associated with ARDS mortality [22]. Therefore, it has been proposed that 
strategies aimed at reducing driving pressure could improve mortality, but this is matter of debate [23]. In our analysis, we observed that patients in the intervention group received significantly higher PEEP at all the analysed time points until day 7 , although the magnitude of such difference decreased over time. This resulted in a reduction of driving pressure of as little as $1 \mathrm{cmH}_{2} \mathrm{O}$ at days 1 and 3, and this difference was no longer significant at day 7. Driving pressure was proposed as a surrogate of dynamic strain; thus, its reduction through lung recruitment, achieved with higher PEEP or RMs, could be lung protective. Nevertheless, few studies described the magnitude of PEEP change resulting from the PEEP titration method, and the effect of PEEP could have been confounded by the fact that some patient received the treatment, according to the intervention arm protocol, also in case of a limited or absent response to PEEP (i.e. driving pressure reduction or oxygenation improvement). Thus, it is possible that the price paid in terms of exposure to higher static strain and barotrauma during RMs offsets the benefits of obtaining an 'open lung' [24]. Moreover, it has been recently observed that in ARDS patients admitted to the intensive care unit, differently from experimental models where PEEP is set immediately after the induction of lung injury, part of the lung collapse cannot be reverted after reaching $40 \mathrm{cmH}_{2} \mathrm{O}$ airway pressure, thus questioning the possibility of achieving an 'open lung' [25]. In a single study, PEEP was titrated based on the oesophageal pressure, and this resulted in a much wider distribution of PEEP levels [19]. However, when this strategy was compared to a higher $\mathrm{PEEP} / \mathrm{FIO}_{2}$ table in a larger cohort, no differences in mortality were observed [26]. We opted not to include the latter trial in the present meta-analysis because it did not fulfil the inclusion criteria, as the control group received higher PEEP, PEEP levels in the intervention and control groups were similar and the aim was to individualise rather than indiscriminately increasing the PEEP level.

In the meta-regression, the PEEP difference between intervention and control group at day 1 was not associated with increased risk of barotrauma. Moreover, in the study in which the incidence of barotrauma was the highest [17], PEEP difference was as low as $3 \mathrm{cmH}_{2} \mathrm{O}$ immediately after randomisation. Some authors proposed that the increased incidence of barotrauma and the higher mortality observed in the intervention group of such study could be explained by alveolar recruitment manoeuvres, not by the PEEP difference [27]. In that trial, the RMs were performed with an abrupt increase of PEEP to $35 \mathrm{cmH}_{2} \mathrm{O}$ [17]. In this line, an abrupt increase of PEEP is associated with lung inflammation in experimental ARDS [28] and increased postoperative pulmonary complications in obese patients [29]. Three previous high-quality meta-analyses concluded that RMs could decrease mortality in ARDS patients, although evidence is inconclusive and of low quality $[10,30,31]$. However, none of these meta-analyses included the most recent trials $[17,18]$, and in only single study RMs were used without other cointerventions, with no effects on 28-days or in-hospital mortality [20]. Moreover, as detailed in Table 1, different techniques of recruitment manoeuvres were used in the 6 studies comprising them in the intervention arm. We cannot exclude that the type of recruitment manoeuvre can influence the clinical outcome and the level of PEEP identified as 'best PEEP'.

The trial sequential analysis showed that the optimum sample size was reached, though the high heterogeneity of techniques for setting PEEP and performing RMs across studies suggests caution before considering evidence as definitive. The 
generalisability of the findings of this meta-analysis could be limited by some factors: (1) we were unable to analyse patient data individually; thus, we could have missed specific sub-groups of patients in which higher PEEP and/or RMs are beneficial; (2) in most trials, ARDS criteria were only assessed at inclusion; thus, its incidence could have been over-estimated; (3) in several studies, very severe patients were excluded; (4) several secondary outcomes could not be assessed systematically and (5) the type of recruitment manoeuvre differed across trials.

\section{Conclusions}

The current evidence does not support the routine use of higher PEEP levels and recruitment manoeuvres in unselected patients with ARDS who are mechanically ventilated with protective low tidal volume.

\section{Supplementary information}

Supplementary information accompanies this paper at https://doi.org/10.1186/s40635-020-00322-2.

Additional file 1. Additional analyses.

\section{Abbreviations}

ARDS: Acute respiratory distress syndrome; ICU: Intensive care unit; PEEP: Positive end-expiratory pressure; RCT: Randomized controlled trial; RM: Recruitment manoeuvre; TSA: Trial sequential analysis

\section{Acknowledgements}

None

\section{About this supplement}

This article has been published as part of Intensive Care Medicine Experimental Volume 8 Supplement 1, 2020: Proceedings from the Fourth International Symposium on Acute Pulmonary Injury and Translation Research (INSPIRES IV). The full contents of the supplement are available at https://icm-experimental.springeropen.com/articles/ supplements/volume-8-supplement-1.

\section{Authors' contributions}

LB takes responsibility for integrity of data. PP, LB and PRMR designed this study, LB and IF performed the bibliography search. VT, MM, CR and PRMR extracted the data. LB and ASN conducted the statistical analyses. LB, PP, NP, PRMR, MJS and MGA drafted the manuscript. All the authors revised and approved the final version of the manuscript.

Funding

Institutional funding only.

\section{Availability of data and materials}

Availability of data and materials does not apply.

Ethics approval and consent to participate

Ethics approval and consent to participate does not apply.

Consent for publication

Consent for publication does not apply.

\section{Competing interests}

All authors declare that they have no conflict of interest.

\section{Author details}

${ }^{1}$ Department of Surgical Sciences and Integrated Diagnostics, University of Genova, Largo Rosanna Benzi 8, 16131 Genova, Italy. ${ }^{2}$ Anesthesia and Intensive Care, Ospedale Policlinico San Martino IRCCS per I'Oncologia e le Neuroscienze, Genova, Italy. ${ }^{3}$ Department of Intensive Care, Academic Medical Center, University of Amsterdam, Amsterdam, Netherlands. ${ }^{4}$ Department of Critical Care Medicine, Hospital Israelita Albert Einstein, São Paulo, Brazil. ${ }^{5}$ Pulmonary Engineering Group, Department of Anaesthesiology and Intensive Care Medicine, University Hospital Carl Gustav Carus, Technische Universität Dresden, Dresden, Germany. ${ }^{6}$ Mahidol Oxford Tropical Medicine Research Unit (MORU), Mahidol University, Bangkok, Thailand. ${ }^{7}$ Nuffield Department of Medicine, University of Oxford, Oxford, UK. ${ }^{8}$ Laboratory of Pulmonary Investigation, Carlos Chagas Filho Institute of Biophysics, Federal University of Rio de Janeiro, Rio de Janeiro, Brazil. 
Received: 14 July 2020 Accepted: 16 July 2020

Published: 18 December 2020

\section{References}

1. Bellani G, Laffey JG, Pham T et al (2016) Epidemiology, patterns of care, and mortality for patients with acute respiratory distress syndrome in intensive care units in 50 countries. JAMA 315:788-800 https://doi.org/10.1001/jama.2016.0291

2. Cruz FF, Ball L, Rocco PRM, Pelosi P (2018) Ventilator-induced lung injury during controlled ventilation in patients with acute respiratory distress syndrome: less is probably better. Expert Rev Respir Med 1-12. https://doi.org/10.1080/ 17476348.2018 .1457954

3. Dreyfuss D, Saumon G (1998) Ventilator-induced lung injury: lessons from experimental studies. Am J Respir Crit Care Med 157:294-323 https://doi.org/10.1164/ajrccm.157.1.9604014

4. Villar J, Kacmarek RM, Pérez-Méndez L, Aguirre-Jaime A (2006) A high positive end-expiratory pressure, low tidal volume ventilatory strategy improves outcome in persistent acute respiratory distress syndrome: a randomized, controlled trial. Crit Care Med 34:1311-1318 https://doi.org/10.1097/01.CCM.0000215598.84885.01

5. Amato MB, Barbas CS, Medeiros DM et al (1998) Effect of a protective-ventilation strategy on mortality in the acute respiratory distress syndrome. N Engl J Med 338:347-354 https://doi.org/10.1056/NEJM199802053380602

6. The ARDS Clinical Trials Network; National Heart, Lung, and Blood Institute; National Institutes of Health (2000) Ventilation with lower tidal volumes as compared with traditional tidal volumes for acute lung injury and the acute respiratory distress syndrome. The Acute Respiratory Distress Syndrome Network. N Engl J Med 342:1301-1308 https:// doi.org/10.1056/NEJM200005043421801

7. Lachmann B (1992) Open up the lung and keep the lung open. Intensive Care Med 18:319-321

8. Fan E, Del Sorbo L, Goligher EC et al (2017) An Official American Thoracic Society/European Society of Intensive Care Medicine/Society of Critical Care Medicine Clinical Practice Guideline: mechanical ventilation in adult patients with acute respiratory distress syndrome. Am J Respir Crit Care Med 195:1253-1263 https://doi.org/10.1164/rccm.2017030548ST

9. Briel M, Meade M, Mercat A et al (2010) Higher vs lower positive end-expiratory pressure in patients with acute lung injury and acute respiratory distress syndrome: systematic review and meta-analysis. JAMA 303:865-873 https://doi.org/ 10.1001/jama.2010.218

10. Goligher EC, Hodgson CL, Adhikari NKJ et al (2017) Lung recruitment maneuvers for adult patients with acute respiratory distress syndrome. A systematic review and meta-analysis. Ann Am Thorac Soc 14:S304-S311 https:/doi.org/ 10.1513/AnnalsATS.201704-3400T

11. Meade MO, Cook DJ, Guyatt GH et al (2008) Ventilation strategy using low tidal volumes, recruitment maneuvers, and high positive end-expiratory pressure for acute lung injury and acute respiratory distress syndrome: a randomized controlled trial. JAMA 299:637-645 https://doi.org/10.1001/jama.299.6.637

12. Mercat A, Richard J-CM, Vielle B et al (2008) Positive end-expiratory pressure setting in adults with acute lung injury and acute respiratory distress syndrome: a randomized controlled trial. JAMA 299:646-655 https://doi.org/10.1001/jama.299.6. 646

13. Brower RG, Lanken PN, Maclntyre N et al (2004) Higher versus lower positive end-expiratory pressures in patients with the acute respiratory distress syndrome. N Engl J Med 351:327-336 https://doi.org/10.1056/NEJMoa032193

14. Huh JW, Jung H, Choi HS et al (2009) Efficacy of positive end-expiratory pressure titration after the alveolar recruitment manoeuvre in patients with acute respiratory distress syndrome. Crit Care Lond Engl 13:R22 https://doi.org/10.1186/ cc7725

15. Hodgson CL, Tuxen DV, Davies AR et al (2011) A randomised controlled trial of an open lung strategy with staircase recruitment, titrated PEEP and targeted low airway pressures in patients with acute respiratory distress syndrome. Crit Care Lond Engl 15:R133 https://doi.org/10.1186/cc10249

16. Kacmarek RM, Villar J, Sulemanji D et al (2016) Open lung approach for the acute respiratory distress syndrome: a pilot, randomized controlled trial. Crit Care Med 44:32-42 https://doi.org/10.1097/CCM.0000000000001383

17. Writing Group for the Alveolar Recruitment for Acute Respiratory Distress Syndrome Trial (ART) Investigators, Cavalcanti $A B$, Suzumura ÉA et al (2017) Effect of lung recruitment and titrated positive end-expiratory pressure (PEEP) vs low PEEP on mortality in patients with acute respiratory distress syndrome: a randomized clinical trial. JAMA 318:1335-1345 https://doi.org/10.1001/jama.2017.14171

18. Hodgson CL, Cooper DJ, Arabi Y, et al (2019) Maximal recruitment open lung ventilation in acute respiratory distress syndrome (PHARLAP): a phase II, multicenter, randomized, controlled trial. Am J Respir Crit Care Med. https://doi.org/10. 1164/rccm.201901-01090C

19. Talmor D, Sarge T, Malhotra A et al (2008) Mechanical ventilation guided by esophageal pressure in acute lung injury. N Engl J Med 359:2095-2104 https://doi.org/10.1056/NEJMoa0708638

20. Xi X-M, Jiang L, Zhu B, RM group (2010) Clinical efficacy and safety of recruitment maneuver in patients with acute respiratory distress syndrome using low tidal volume ventilation: a multicenter randomized controlled clinical trial. Chin Med J 123:3100-3105

21. Santa Cruz R, Rojas Jl, Nervi R, et al (2013) High versus low positive end-expiratory pressure (PEEP) levels for mechanically ventilated adult patients with acute lung injury and acute respiratory distress syndrome. Cochrane Database Syst Rev CD009098. https://doi.org/10.1002/14651858.CD009098.pub2

22. Amato MBP, Meade MO, Slutsky AS et al (2015) Driving pressure and survival in the acute respiratory distress syndrome. N Engl J Med 372:747-755 https://doi.org/10.1056/NEJMsa1410639

23. Bugedo G, Retamal J, Bruhn A (2017) Driving pressure: a marker of severity, a safety limit, or a goal for mechanical ventilation? Crit Care Lond Engl 21:199 https://doi.org/10.1186/s13054-017-1779-x

24. Pelosi P, Rocco PRM, Gama de Abreu M (2018) Close down the lungs and keep them resting to minimize ventilatorinduced lung injury. Crit Care Lond Engl 22:72 https://doi.org/10.1186/s13054-018-1991-3

25. Cressoni M, Chiumello D, Algieri I et al (2017) Opening pressures and atelectrauma in acute respiratory distress syndrome. Intensive Care Med 43:603-611 https://doi.org/10.1007/s00134-017-4754-8 
26. Beitler JR, Sarge T, Banner-Goodspeed VM et al (2019) Effect of titrating positive end-expiratory pressure (PEEP) with an esophageal pressure-guided strategy vs an empirical high PEEP-Fio2 strategy on death and days free from mechanical ventilation among patients with acute respiratory distress syndrome: a randomized clinical trial. JAMA 321:846-857 https://doi.org/10.1001/jama.2019.0555

27. Barbas CSV, Nemer SN (2018) Lung recruitment and positive end-expiratory pressure titration in patients with acute respiratory distress syndrome. JAMA 319:933 https://doi.org/10.1001/jama.2017.21840

28. Santos RS, Moraes L, Samary CS et al (2016) Fast versus slow recruitment maneuver at different degrees of acute lung inflammation induced by experimental sepsis. Anesth Analg https://doi.org/10.1213/ANE.00000000000001173

29. Ball L, Hemmes SNT, Serpa Neto A et al (2018) Intraoperative ventilation settings and their associations with postoperative pulmonary complications in obese patients. Br J Anaesth 121:899-908. https://doi.org/10.1016/j.bja.2018. 04.021

30. Suzumura EA, Figueiró M, Normilio-Silva K et al (2014) Effects of alveolar recruitment maneuvers on clinical outcomes in patients with acute respiratory distress syndrome: a systematic review and meta-analysis. Intensive Care Med 40:12271240 https://doi.org/10.1007/s00134-014-3413-6

31. Hodgson C, Goligher EC, Young ME et al (2016) Recruitment manoeuvres for adults with acute respiratory distress syndrome receiving mechanical ventilation. Cochrane Database Syst Rev 11:CD006667 https://doi.org/10.1002/14651858. CD006667.pub3

\section{Publisher's Note}

Springer Nature remains neutral with regard to jurisdictional claims in published maps and institutional affiliations.

Submit your manuscript to a SpringerOpen ${ }^{\odot}$ journal and benefit from:

- Convenient online submission

- Rigorous peer review

- Open access: articles freely available online

- High visibility within the field

- Retaining the copyright to your article

Submit your next manuscript at $>$ springeropen.com 